\title{
THE USE OF STEEL CHIPS FROM MACHINING OF STEEL IN A GEOSILICATE COMPOSITE
}

\author{
${ }^{1}$ Iva DUFKOVÁ, ${ }^{1}$ Vladimír KOVAČIČ, ${ }^{2}$ Jiří MAŠEK, ${ }^{1}$ Amanda GASPAR COELHO PINTO \\ ${ }^{1}$ TUL - Technical University of Liberec, Czech Republic, EU, \\ iva.dufkova@tul.cz, vladimir.kovacic@tul.cz
}

2SPŠ-VOŠ - Technical College of Jičín, Czech Republic, EU, masek@vos-sps-jicin.cz

https://doi.org/10.37904/metal.2019.802

\begin{abstract}
In small companies, the machining chips of their production are sometimes not processed. Therefore, their use is discussed in the article. Geopolymers are generally known as materials in which machining waste can be incorporated and they have been used for processing in geopolymer composites. The article is about geosilicate composites made from Baucis Lk filled with steel chips from machining of steel, basalt fibers, sand and $\mathrm{SiO}_{2}$. Furthermore, the paper describes the mechanical properties of these composites. At the same time, the paper describes composites and their mechanical tests filled with steel balls, sand, basalt fibers and $\mathrm{SiO}_{2}$.
\end{abstract}

Keywords: Geosilicate, steel chips, steel balls, composite

\section{INTRODUCTION}

Geopolymers are defined as alkali activated aluminosilicates in the form of metakaolin, fly ash, blast furnace slag and other ingredients. They consist of chains or networks of mineral molecules linked with covalent bonds. The raw materials are mainly minerals of geological origin, hence the name "geopolymer". They comprise several molecular units for example: silico-oxide ( $\mathrm{Na}, \mathrm{K})-(-\mathrm{Si}-\mathrm{O}-\mathrm{Si}-\mathrm{O}-)$ for $(\mathrm{Na}, \mathrm{K})$-poly(silicate) or ( $\mathrm{Na}, \mathrm{K})-$ poly(siloxonate), silico-aluminate ( $\mathrm{Na}, \mathrm{K})-(-\mathrm{Si}-\mathrm{O}-\mathrm{Al}-\mathrm{O})$ for ( $\mathrm{Na}, \mathrm{K})$-poly(sialate), ferro-silico-aluminate ( $\mathrm{Na}, \mathrm{K}$ )(-Fe-O-Si-O-Al-O-) or ( $\mathrm{Na}, \mathrm{K}$ )-poly(ferro-sialate), alumino-phosphate (-Al-O-P-O-) for poly(aluminophosphate), formed in a geopolymerization process [2]. The most common activator is water glass with other alkalis. These peculiar materials (geopolymer) are now tested and used for their outstanding properties. For example during the Grand Prix season 1994 and 1995, Benetton-Renault Formula 1 Sport Car designed a unique thermal shield made out of carbon/geopolymer composite. It helped Michael Schumacher to win twice the world championship and offered to his technical team to become World Champion of car builders during these two years. Still today, most Formula 1 teams are using geopolymer composite materials. [3].

Geopolymers got their name in 1970 when Davidovich termed the alkali activated aluminosilicates. Their general formula is $\mathrm{Mn}\{-(\mathrm{SiO} 2) \mathrm{z}-\mathrm{AlO} 2\} n$. wH2O, where usually $\mathrm{M} \approx 1$ and $2 \leq n \leq 6$. The letter $\mathrm{M}$ represents one or more alkali metals. In the industrial waste, especially in slags or fly ash, cations $\mathrm{Ca} 2+$ are to be found. Letter " $n$ " is a degree of polycondensation, " $z$ " is $1,2,3$ or higher up to 32 . Geopolymers - alkali activated systems - can be prepared both from the metakaolins and from the waste [4,5]. For example, waste materials are preferably incorporated into geopolymer composites. It has been proved that the layer of geopolymer applied on chipboard prevents the burning through for more than 30 minutes [1]. Two types of samples we did in our research. In the first type of samples we used steel chips from machining of steel ČSN 11300, sand, basalt fibers and $\mathrm{SiO}_{2}$ as filling into geopolymer and in the second samples we used steel balls, sand, basalt fibers and $\mathrm{SiO}_{2}$. One type of waste are metal shavings from machining that are shipped for recycling in large companies, but recycling is a problem for small businesses. Advantageously, these wastes can be used as fillers in geopolymer composites where they improve their mechanical properties and ultimately allow these composites to perform new functions. Steel chips from steel ČSN 11300 for geopolymer integration were chosen for this work and geopolymer composite with steel ball blasting was created for comparison. 


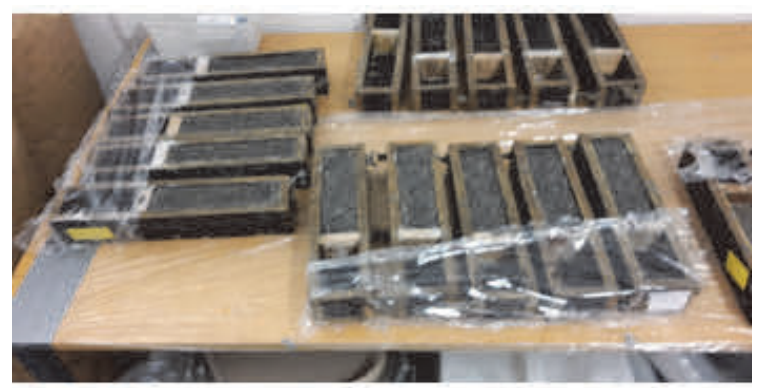

Figure 1 Forms 50x50×150 mm with mixure

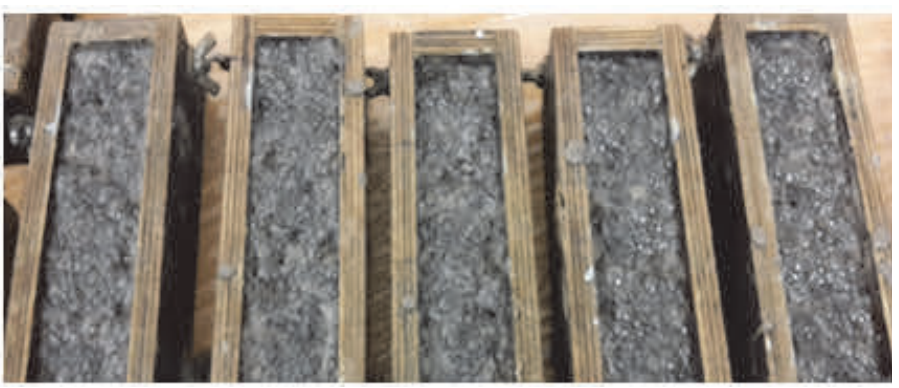

Figure 2 Unwraped forms with mixure

\section{EXPERIMENTAL PART}

Operating fluids were removed from the steel chips before use with petroleum ether. The steel chips were with a volume coefficient of 4-6. The basic mixture was stirred for $15 \mathrm{~min}$. Steel chips (granules) were then added. After pouring the mixture into $50 \times 50 \times 150 \mathrm{~mm}$ forms (Figure 1 and Figure 2), the forms were wrapped. After 5 days, the samples were unform and wrapped given to dry to the oven at $45^{\circ} \mathrm{C}$ for 24 hours. Compressive strength measurements were performed according to EN 1015-11. Determination of flexural and compressive strength of hardened mortars. The compression strength test was performed by compression between two 42 $x 42 \times 3 \mathrm{~mm}$ steel jaws maschine at the ends of the beams.

Subsequently, the samples were unwrapped (Figure 1) and returned to an oven at $82{ }^{\circ} \mathrm{C}$ for 24 hours. After being removed from the oven, the samples were left in the air for further 15 days. Compression and flexural strength tests were performed on the samples. In Table 1 and Table 2, we can see the ratio of results obtained from these measurements for individual samples.

Table 1 Compressive strength of samples filled with steel balls

\begin{tabular}{|c|c|c|c|}
\hline Sample & $\begin{array}{c}\text { Compressive strength } \\
(\mathbf{M P a})\end{array}$ & Standard deviation (MPa) & $\begin{array}{c}\text { Confidence } \\
\text { (MPa) }\end{array}$ \\
\hline 0.00 & 25.1 & 4.0 & 1.6 \\
\hline 0.01 & 27.8 & 4.3 & 1.6 \\
\hline 0.03 & 20.0 & 5.2 & 2.3 \\
\hline 0.05 & 26.7 & 5.0 & 1.9 \\
\hline
\end{tabular}

Table 2 Compressive strength of samples filled with steel chips

\begin{tabular}{|c|c|c|}
\hline Quantity of steel chips & $\begin{array}{c}\text { Average compressive strength } \\
\text { (MPa) }\end{array}$ & $\begin{array}{c}\text { Average flexural strength } \\
\text { (MPa) }\end{array}$ \\
\hline 0 & 25.1 & 0.969 \\
\hline 1 & 34.0 & 1.009 \\
\hline 3 & 23.6 & 0.884 \\
\hline 5 & 22.5 & 0.924 \\
\hline
\end{tabular}

Sample 1 with $0 \%$ is Baucis Lk with activator, sand, $\mathrm{SiO}_{2}$, and basalt fibers. Figure 3 and Figure 4 show the comparison of the individual samples after the crush strength test. Figure $\mathbf{5}$ and Figure $\mathbf{6}$ show a comparison of bending strength results. 


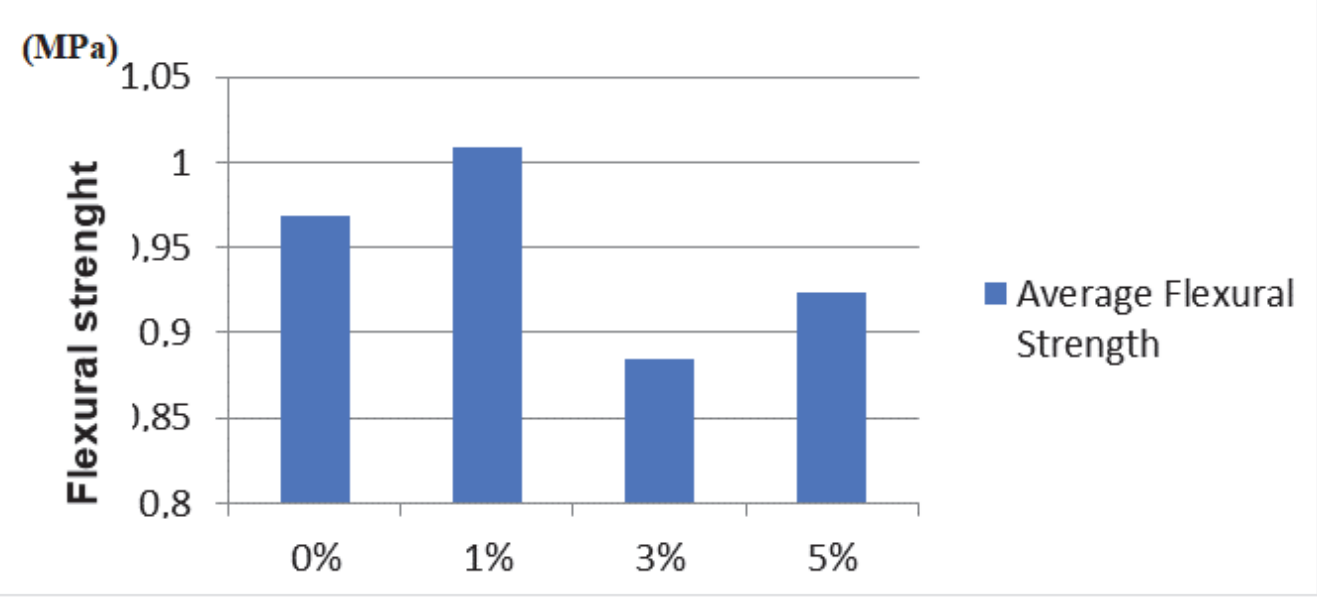

Figure 3 Average Flexural Strength of Composite with Steel Chips

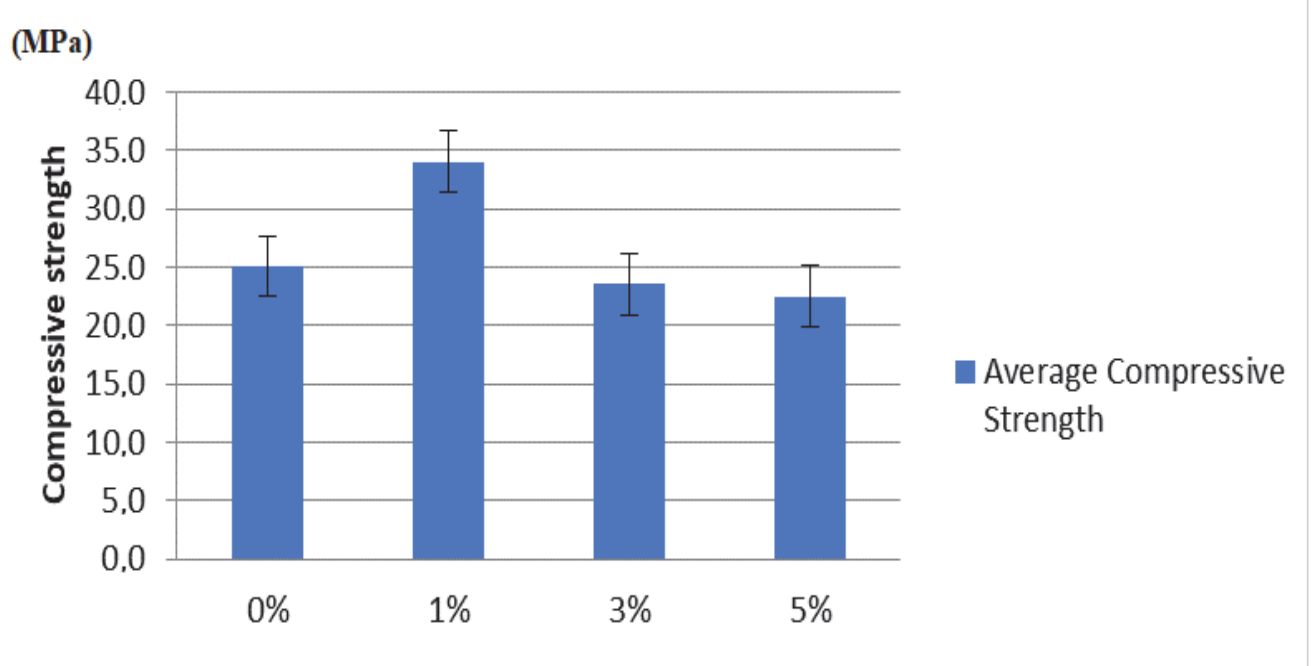

Figure 4 Average Compressive Strength of Composite with Steel Chips

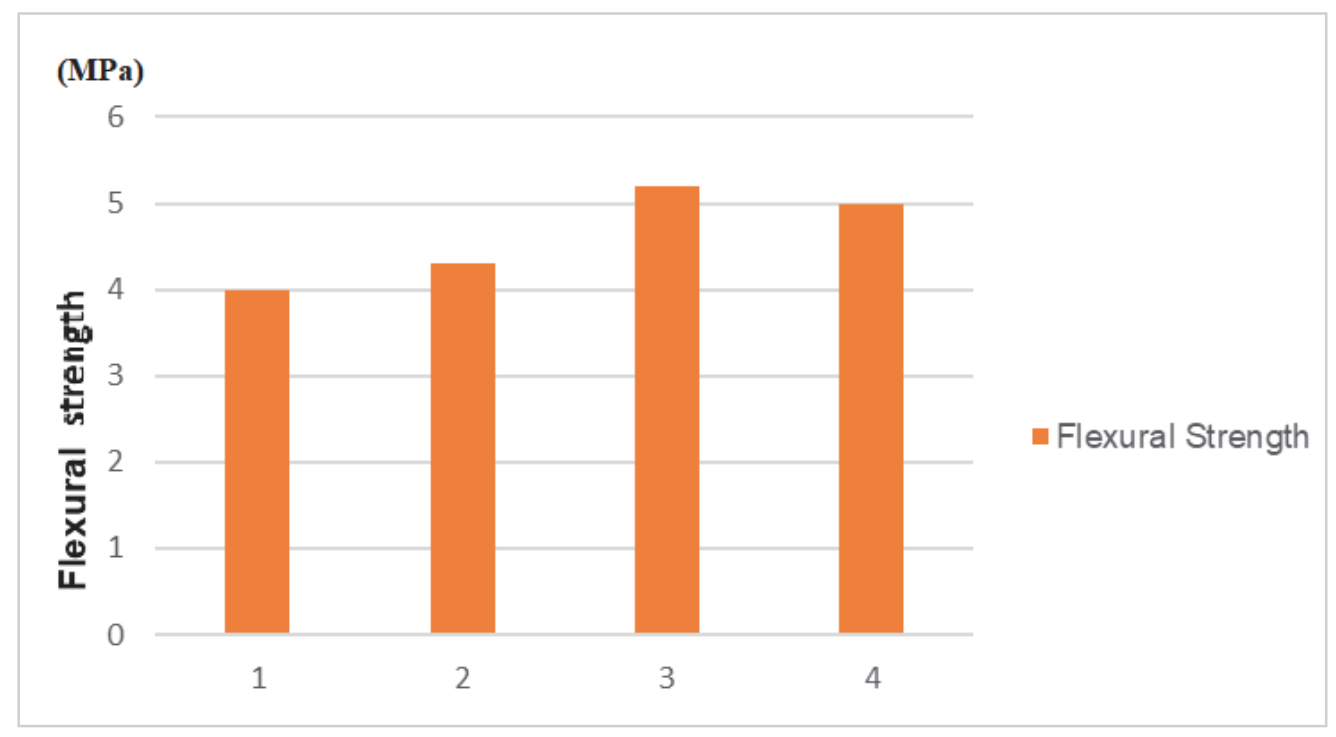

Figure 5 Average Flexural Strength of Composite with Steel Balls 


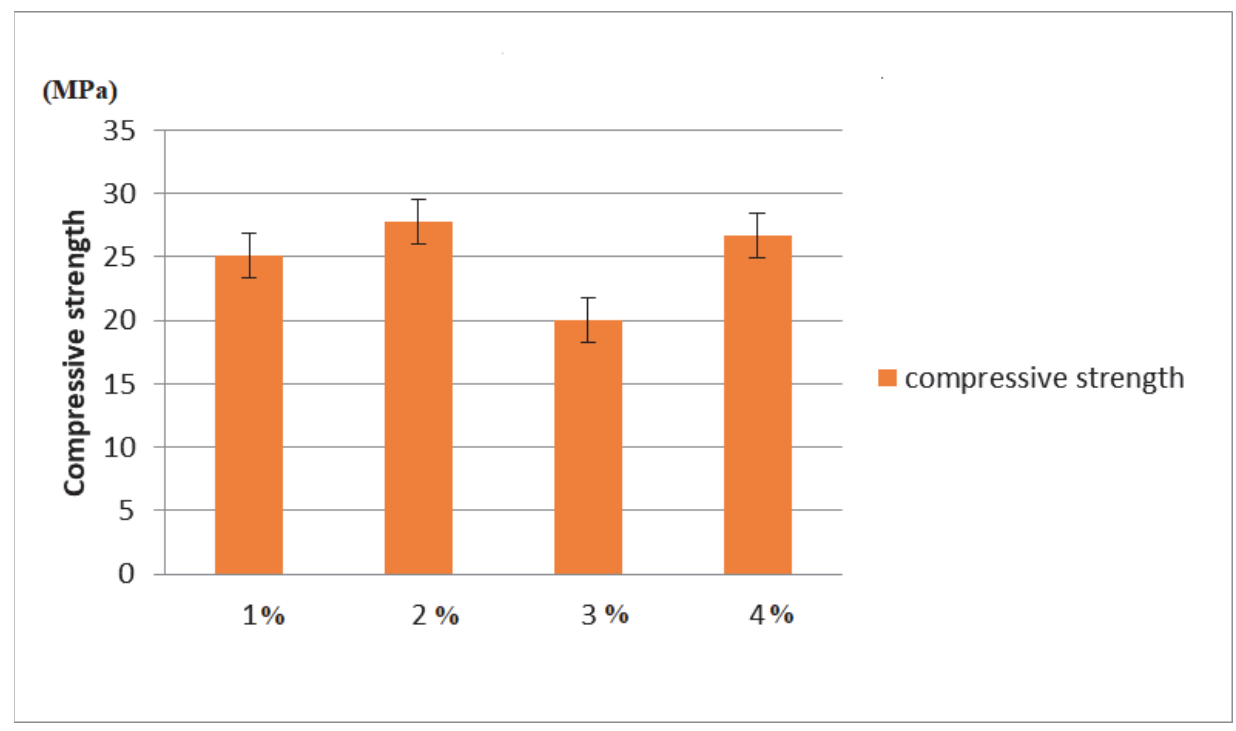

Figure 6 Average Compressive Strength of Composite with Steel Balls

\section{CONCLUSION}

It can be seen from the above tables and graphs that by adding steel chips at $1 \%$, the bending strength of the geopolymer composite increases by $15 \%$. With a higher addition of steel chips, the bending strength decreases due to structural inequalities. The same applies to the strength of steel chip composites. Compressive strength increases by $35 \%$. The geopolymer composite with steel granulates in the form of steel balls shows an increase in compressive strength at $2 \%$ of its content (by $11 \%$ ). Here, due to the particular character of the filler, it is better fixing in the composite matrix. However, it should be noted that standard deviation is almost overlapping. This reduces the statistical credibility of the strength increase.

It has been confirmed that the addition of steel chips as a geopolymer composite filler increases flexural strength and compression. It is suggesting to use steel waste in these composites.

\section{ACKNOWLEDGEMENTS}

The results of the project „Application of geopolymer composites as fire, AGK", registration number VI20172019055, were obtained through the financial support of the Ministry of Interior in the program "The Safety Research of the Czech Republic" 2015-2020 (BV III/1-VS).

\section{REFERENCES}

[1] DUFKOVÁ, Iva, KOVAČIČ, Vladimír, BILKETAY, S., KROISOVÁ, D. Use of Geopolymer Matrix Composites in the Construction of Fire Doors. Key Engineering Materials. 2015. vol. 635, pp. 174-176.

[2] DAVIDOVITS, Joseph, Geopolymers: Ceramic-like inorganic polymers. Journal of Ceramic Science and Technology. 2017. vol. 8, no. 3, pp. 335-350.

[3] GEOPOLYMER INSTITUT, [online]. Fire proof, heat resistant composites, Last updated: 07 April 2006. Saint Quentin: [viewed 2019-07-24]. Available from: https://www.geopolymer.org/applications/fire-proof-heat-resistantcomposites/

[4] DAVIDOVITS, Joseph. Geopolymers. Inorganic Polymeric New Materials. J. Therm. Analysis. 1991. vol. 37, pp. 1633-1656.

[5] DAVIDOVITS, Joseph, DAVIDOVIES Michael. Geopolymer Room Temperature Ceramic Matrix for Composities. Ceramic Engineering and Science Proceedings. 1988, vol. 9, no. 7-8, pp. 835-842. 